\title{
Mooring Analysis of Offshore Aquaculture Oceanic Farming Platform for Seaweed
}

\author{
Sulaiman OO $^{1 *}$, Kader ASA ${ }^{2}$, Magee $\mathrm{A}^{3}$ and Othman $\mathrm{K}^{4}$ \\ ${ }^{1}$ Department of Maritime Technology, Faculty of Maritime Studies and Marine Science, Universiti Malaysia Terengganu, 21030, Kuala Terengganu, Malaysia \\ ${ }^{2}$ Department of Marine Technology, Faculty of Mechanical Engineering, Universiti Teknologi Malaysia, 81300, Skudai, Johor, Malaysia \\ ${ }^{3}$ Technip Corporation, Jalan Tun Razak, Kuala Lumpur, Malaysia Bureau Veritas Corporation, Kuala Lumpur, Malaysia \\ ${ }^{4}$ Bureau Veritas Corporation, Kuala Lumpur, Malaysia
}

\begin{abstract}
Aquaculture activities are performed at close proximity to coastline and near shore. Issues and environmental impact concerns and challenges necessitate offshore aquaculture that required reliable structural integrity and mooring system design for ultimate state limit, fatigue state limit and accidental and progressive state limit against environmental loading and accidental loading. To avoid mooring system failure, selecting an appropriate breaking strength and limit state for mooring system components is necessary. Suitable mooring system has been designed by group of researchers at Universiti Malaysia Terengganu. Valuable information was obtained from Technip and Bureau Veritas. The system has been tested in towing tank in Universiti Teknologi Malaysia. This paper describes mooring system design that account for forces and environmental loadings. The paper describes evaluation of optimum mooring performance in wave and current loadings on mooring components anchor buoy and riser elements that are involved in the mooring system dynamics.
\end{abstract}

Keywords: Aquaculture; Dynamic loading; Marine; Offshore; Structure

\section{Introduction}

Floating offshore aquaculture farms drift at the mercy of ocean currents, wind and waves. They are designed to move easily up and down in a vertical motion that can range up to several meters under normal sea conditions and tens of meters during a storm. Although these systems can be positioned at depths that avoid storm damage, a major challenge of such floating systems is the uncertainly of where the farms may end up after a storm. There has been renewed interest in floating farms in recent years as platforms and technologies have improved to withstand open ocean conditions. Almost all that were moderately successful have combined a floating platform with a tethered or anchored component [1]. Most aquaculture systems are tethered to the sea floor through anchors, floats and lines.

Recently, large scale cultivation of seaweed have been developed to meet the increasing market demand and at the same time to provide alternative livelihood schemes for local populations. The large farming expansion near onshore is likely to bring so much problem. In some cases, unfavorable environmental factors such as near shore pollution from sewage pushes marine farming sites further offshore to water depths of $50 \mathrm{~m}$ or greater. Thus the need to move operations into more exposed sites and in totally unprotected open sea may have to face devastating natural disasters caused by tropical storms is becoming necessary. In non-stationery offshore structure, wave, current and wind forces increase rapidly [2]. This means that maximum wave heights of 5-10 m, current speed of 2-3 knots and wind speed of $35 \mathrm{~m}$ $\mathrm{s}^{-1}$. This situation can occur at the same time and in the same direction. A requirement is, therefore, that the farming unit may be able to withstand conditions like these. Mooring system design is a tradeoff between making the system compliant enough to avoid excessive forces on the farming platform, and making it stiff enough to avoid difficulties, such as damage caused by excessive horizontal excursions of the farming platform.
This study use South China sea, Terengganu as a case study. The study site is 200 meters off the beach of Kampung Telaga Papan. Telaga Papan is fishing village. The local people are very interested to perform large seaweed plantation. The location is exposed to North East strong wave during monsoon season (Figure 1).

\section{Mooring geometry}

Design criteria specific for the site in the coast of Setiu was established

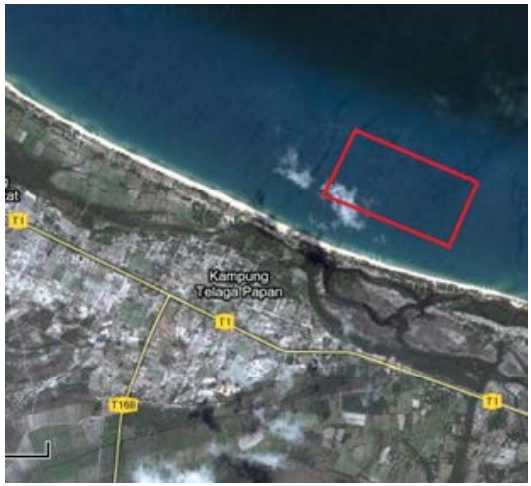

Figure 1: Location of research area.

*Corresponding author: Sulaiman OO, Department of Maritime Technology, Faculty of Maritime Studies and Marine Science, Universiti Malaysia Terengganu, 21030, Kuala Terengganu, Malaysia, Tel: +609668-3697/+60177244339; Fax: +609-6683193; E-mail: o.sulaiman@umt.edu.my

Received December 12, 2014; Accepted March 23, 2015; Published March 30, 2015

Citation: Sulaiman OO, Kader ASA, Magee A, Othman K (2015) Mooring Analysis of Offshore Aquaculture Oceanic Farming Platform for Seaweed. J Coast Zone Manag 18: 399. doi: 10.4172/2473-3350.1000399

Copyright: (c) 2015 Sulaiman OO, et al. This is an open-access article distributed under the terms of the Creative Commons Attribution License, which permits unrestricted use, distribution, and reproduction in any medium, provided the original author and source are credited. 
prior to the engineering analysis and specification of components. It is necessary that the new mooring be able to accommodate $100 \mathrm{mx}$ $1000 \mathrm{~m}$ planting block shape, the block had to be able to withstand the waves and currents that occur at the site, especially those associated with extreme storms. The mooring system also needs to be designed to minimize entanglement of seaweed planting. The design constraint required that the mooring system be deployed in the existing permitted site approximately 200 meter from the shore. The site is 10-50 meter of water depth and the bottom composition consists of relatively heterogeneous materials, which include bedrock outcroppings, gravel and muddy sands. Figure 2 shows the top view of the mooring system [3].

\section{Mooring analysis}

For this study, current is considered because of the dominant contribution of load compared with wave and wind. Static current loads are discussed in detail below. Static loads due current are separated into longitudinal load and lateral load. Flow mechanisms which influence these loads include main rope drag, main buoy drag, seaweed drag, and planting lines drag [4].

Total load is determined using the following equation:

$$
\mathrm{F}_{\text {total }}=\mathrm{F}_{\text {main rope }}+\mathrm{F}_{\text {byoy }}+\mathrm{F}_{\text {loadliness }}+\mathrm{F}_{\text {seaweed }}
$$

The analysis of cables, or mooring lines that maintain surface and subsurface platform on station, is the study of the loads exerted on the lines by gravitational and time-invariant current fields and of their resulting effects. This study allows one to predict the geometry of the line between the structure and its anchoring point and the distribution of stresses from top to bottom. The study of mooring cable addresses the two-dimensional cases where the line and the current can be

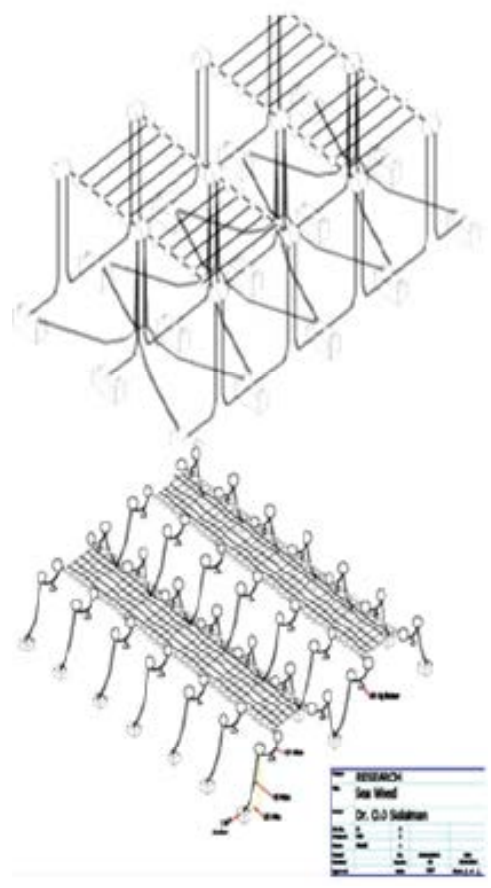

Figure 2: Mooring geometry. assumed to be coplanar [5]. Forces that need to be considered are the immersed weight or the resultant gravity force per unit of cable length is usually defined as

$$
\mathrm{P}=\mathrm{B}_{\mathrm{c}}-\mathrm{W}_{\mathrm{c}}
$$

Where:

$\mathbf{B}_{\mathbf{C}}=$ is cable buoyancy per foot that is the weight of the water displaced by one foot of cable, $\mathbf{W}_{\mathrm{C}}=$ is "air weight" of one foot of cable.

The hydrodynamic resistance due to current passing a cable element of diameter and the length, when normal to the flow as shown in the Figure 3 is given by:

$$
\mathrm{Rds}=\frac{1}{2} \rho \mathrm{C}_{\mathrm{DN}} \mathrm{dV}^{2} \mathrm{ds}
$$

where: $\mathrm{C}_{\mathrm{DN}}=$ Normal drag coefficient, $\mathrm{V}=$ Current speed.

If the cable element is at an angle $\varphi$ from the current horizontal direction, its resistance can be considered to be made of two components: one normal and one tangential to the cable.

The normal component is given by

$$
\text { Dds }=\frac{1}{2} \rho C_{D N} d V^{22} \sin \varphi d s
$$

$$
\mathrm{R}^{\sin ^{2} \phi d s}
$$

and tangential component given by

$$
\mathrm{Fds}=\frac{1}{2} \rho \gamma \mathrm{C}_{\mathrm{DN}}(\pi \mathrm{d}) \mathrm{V}^{22} \cos \varphi \mathrm{ds}=\pi \gamma \cos ^{2} \varphi \mathrm{ds}
$$

where: $\boldsymbol{\rho} \boldsymbol{\gamma} \mathbf{C}_{\mathrm{DN}}=$ the tangential drag coefficient, $(\boldsymbol{\pi d}) \mathbf{d s}=$ the "skin" or longitudinal area of the cable element.

For equilibrium to prevail the tension, $\mathbf{T}_{\mathbf{1}}$, in the segment must be

$$
\mathrm{T}_{1}=\left[\mathrm{R}_{\mathrm{X}(0)}{ }^{2}+\mathrm{R}_{\mathrm{Z}(0)}{ }^{2}\right]^{\frac{1}{2}}
$$

Knowing that this segment is in line with the tension vector at its upper end, its inclination is given by

$$
\theta_{1}=\tan ^{-1}\left[\frac{R_{z(0)}}{R_{x(0)}}\right]
$$

Under the action of the pull $T_{1}$ the segment stretches to a length $S_{(1)}$

$$
\mathrm{S}_{(1)}=\mathrm{L}_{(1)}+\Delta \mathrm{L}_{(1)}
$$

where: $\mathbf{L}_{(1)}=$ segment original length, $\Delta \mathbf{L}_{(1)}=$ elongation resulting from the applied tension.

In order to determine the hydrodynamic coefficient of the design, the rows of seaweed are held using ropes separated by about $2.6 \mathrm{~m}$ between rows. A frame consisting of aluminium channel sections

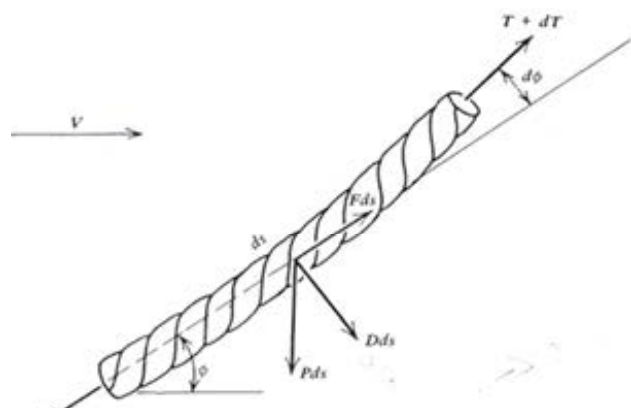

Figure 3: Forces on cable element. 
Citation: Sulaiman OO, Kader ASA, Magee A, Othman K (2015) Mooring Analysis of Offshore Aquaculture Oceanic Farming Platform for Seaweed. J Coast Zone Manag 18: 399. doi: 10.4172/2473-3350.1000399

Page 3 of 4

attached to the towing carriage is used. The seaweed clumps then attached to a rope line. Tension load cells will be attached between the line and the frame and the measured forces recorded on the model basin's data acquisition system. Figures 4 and 5 show the aluminium test frame to hang the seaweed.

\section{Results and Discussion}

Table 1 show the data of the structure component used in this study. The full scale data were used to calculate the environment load on one block structure. Normal drag coefficient is used for the longitudinal load on the structure which is 90 degree. This is because 90 degree is considered maximum load. Tangential drag coefficient is used for the lateral load on the structure which is 0 degree. 0 degree is considered minimum load on the structure.

\section{Mooring line properties}

Table 2 shows the mooring line data used in this research. Type of mooring line used is the polyester rope. Other type of mooring line that normally used for moored platform is chain and wire rope. Water

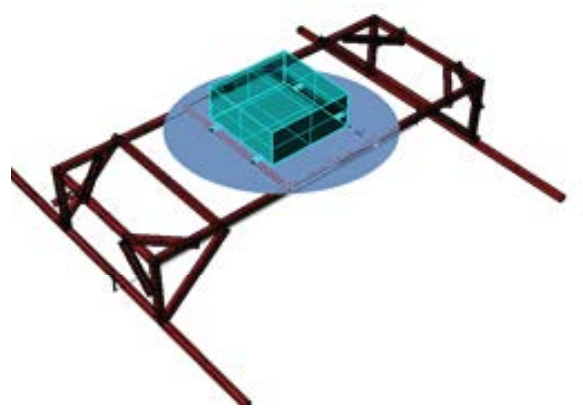

Figure 4: The aluminium test frame.

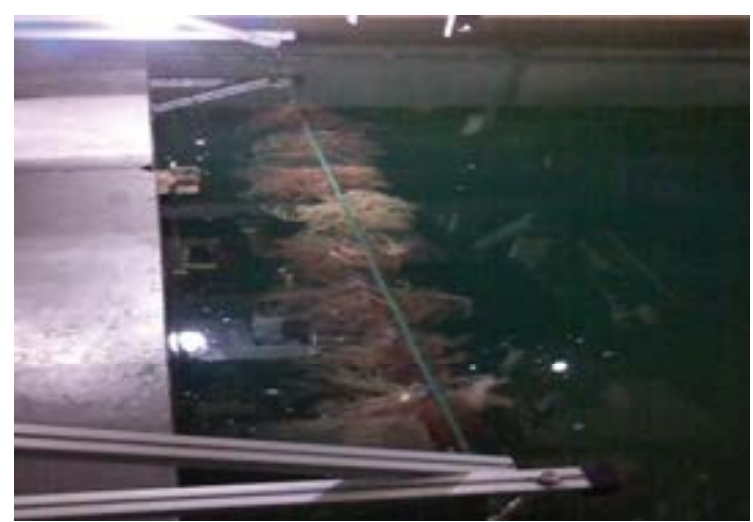

Figure 5: Test frame with seaweed attached.

\begin{tabular}{|c|c|c|c|c|c|}
\hline & $\begin{array}{c}\text { Length } \\
(\mathbf{m})\end{array}$ & $\begin{array}{c}\text { Diameter } \\
(\mathbf{m})\end{array}$ & $\begin{array}{c}\text { Effective } \\
\text { area } \\
\left(\mathbf{m}^{2} \mathbf{)}\right.\end{array}$ & $\begin{array}{c}\text { Normal drag } \\
\text { coefficient } \\
\left(\mathbf{C}_{\mathbf{d n}} \mathbf{)}\right.\end{array}$ & $\begin{array}{c}\text { Tangential drag } \\
\text { coefficient }\left(\mathbf{C}_{\mathrm{dt}} \mathbf{)}\right.\end{array}$ \\
\hline Main bouy & - & 0.16 & 2.2 & 0.8 & 0.8 \\
\hline Main rope & 100 & 0.022 & 0.8 & 1.3 & 0.008 \\
\hline Load line rope & 100 & 0.008 & 0.020 & 1.3 & 0.008 \\
\hline Seaweed plant & 100 & - & 0.125 & 0.18 & - \\
\hline
\end{tabular}

Table 1: Component properties.

\begin{tabular}{|c|c|c|}
\hline Mooring Line Data & Value & Units \\
\hline Effective area of mooring line & 0.0015 & $\mathrm{~m}^{2}$ \\
\hline Diameter of mooring line, $\mathrm{D}_{\mathrm{c}}$ & 0.022 & $\mathrm{~m}$ \\
\hline Length of mooring line & 50 & $\mathrm{~m}$ \\
\hline Mean sea level & 50 & $\mathrm{~m}$ \\
\hline Young modulus of mooring line & $132 \times 10^{8}$ & $\mathrm{~N} / \mathrm{m}^{2}$ \\
\hline Segment length, $\mathrm{L}_{\mathrm{n}}$ & 1 & $\mathrm{~m}$ \\
\hline
\end{tabular}

Table 2: Mooring cable data.

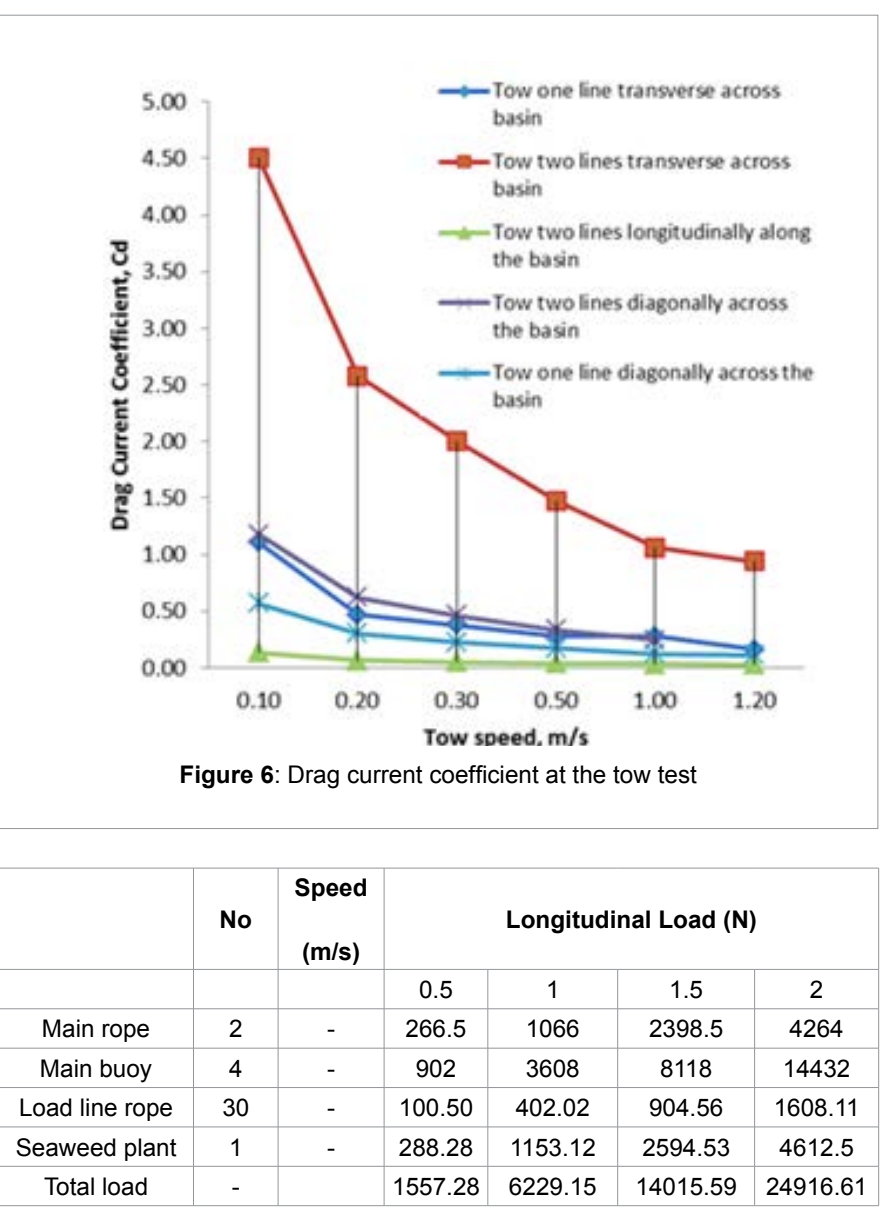

Table 3: Longitudinal current load.

\begin{tabular}{|c|c|c|c|c|c|c|}
\hline & No & Speed (m/s) & \multicolumn{4}{|c|}{ Lateral Load (N) } \\
\hline & & & 0.5 & 1 & 1.5 & 2 \\
\hline Main rope & 2 & - & 266.5 & 1066 & 2398.5 & 4264 \\
\hline Main buoy & 4 & - & 902 & 3608 & 8118 & 14432 \\
\hline Load line rope & 30 & - & 0.6185 & 2.474 & 5.5665 & 9.8960 \\
\hline Seaweed plant & 30 & - & 86.48 & 345.93 & 778.359 & 1383.75 \\
\hline Total load & & & 1255.60 & 5022.41 & 11300.42 & 20089.64 \\
\hline
\end{tabular}

Table 4: Lateral Current Load.

depth value to the seabed is 50 meters.

Figure 6 shows that the drag current coefficient of tow two lines transverse across the basin is higher than other four test cases. This is because tow line transverse across the basin has more resistance compared to tow two lines longitudinally and tow two lines diagonally across the basin. Furthermore, for tow one line, tow one line transverse across the basin has more drag current coefficient compared to tow 
Citation: Sulaiman OO, Kader ASA, Magee A, Othman K (2015) Mooring Analysis of Offshore Aquaculture Oceanic Farming Platform for Seaweed. J Coast Zone Manag 18: 399. doi: 10.4172/2473-3350.1000399

one line diagonally across the basin. It can be concluded that, at the transverse direction the drag current coefficient is higher than longitudinally and diagonally direction. Hence, the transverse direction should be highly considered.

\section{Current load analysis}

Four samples of current speed are taken (Table 3). The current speeds start with $0.1 \mathrm{~m} / \mathrm{s}, 1 \mathrm{~m} / \mathrm{s}, 1.5 \mathrm{~m} / \mathrm{s}$ and $2 \mathrm{~m} / \mathrm{s}$. The maximum longitudinal current load occurs when the structure facing $2 \mathrm{~m} / \mathrm{s}$ of current speed which has the value of close to $25 \mathrm{kN}$.

Table 4 shows the lateral current load. From Table 4, four samples of current speed are taken. The current speeds start with $0.1 \mathrm{~m} / \mathrm{s}, 1 \mathrm{~m} / \mathrm{s}$, $1.5 \mathrm{~m} / \mathrm{s}$ and $2 \mathrm{~m} / \mathrm{s}$. The maximum lateral current load occurs when the structure facing $2 \mathrm{~m} / \mathrm{s}$ of current speed which has the value of $20 \mathrm{kN}$.

\section{Conclusions}

A station keeping analysis is performed to determine the suitable mooring component to be equipped on the seaweed farming. Model test is carried out to determine environmental loading requirement of the system. Mooring behavior and its performances are determined for the feasibility of deploying floating structure for offshore aquaculture in exposed sites. The analysis serves as the basis for comparing and evaluating mooring systems tension.

\section{References}

1. Buck BH, Smetacek V (2006) Aquafarm Roter Sand. Alfred-WegenerInstitut fur Polar-und Meeresforschung.

2. North WJ (1987) Oceanic farming of Macrocystis, the problems and nonproblems. In Seaweed Cultivation for Renewable Resources, Amstedam; 3997

3. Sulaiman OO, Allan Magee MIAR, Wan NWB (2012) Preliminary Design and Prototype Scale Model of Offshore Acquaculture Floating Structure for Seaweed Ocean Farming, ICSOT. Developments In Fixed \& Floating Offshore Structures, Busan, Korea.

4. Chakrabarti R (2005) Handbook of offshore engineering (1 $1^{\text {st }}$ edtn).

5. Skop RA (1988) Mooring system: a state of the art review. J Offshore Mechanical Arctic Eng 110; 365-372. 